Canadian University Music Review

Revue de musique des universités canadiennes

\title{
Daniele Pistone. Heugel et ses musiciens : lettres à un éditeur parisien. Paris : Presses Universitaire de France, 1984, 128 pp.
}

\section{Susan Spier}

Numéro 6, 1985

URI : https://id.erudit.org/iderudit/1014069ar

DOI : https://doi.org/10.7202/1014069ar

Aller au sommaire du numéro

Éditeur(s)

Canadian University Music Society / Société de musique des universités

canadiennes

ISSN

0710-0353 (imprimé)

2291-2436 (numérique)

Découvrir la revue

Citer ce compte rendu

Spier, S. (1985). Compte rendu de [Daniele Pistone. Heugel et ses musiciens : lettres à un éditeur parisien. Paris : Presses Universitaire de France, 1984, 128 pp.] Canadian University Music Review / Revue de musique des universités canadiennes, (6), 326-327. https://doi.org/10.7202/1014069ar

(C) Canadian University Music Society / Société de musique des universités canadiennes, 1985
Ce document est protégé par la loi sur le droit d'auteur. L'utilisation des services d'Érudit (y compris la reproduction) est assujettie à sa politique d'utilisation que vous pouvez consulter en ligne.

https://apropos.erudit.org/fr/usagers/politique-dutilisation/ 
Daniele Pistone. Heugel et ses musiciens : lettres à un éditeur parisien.

Paris : Presses Universitaire de France, 1984, 128 pp.

Ce mince volume sera apprécié comme livre de source par tous ceux qui portent un intérêt particulier au milieu artistique et musical de l'Europe du XIXe siècle. Comme le titre le suggère, il s'agit d'une collection de lettres ( 72 sur les 4000 recensées), adressées par trente quatre auteurs différents à l'éditeur parisien bien connu, Heugel.

Le livre s'ouvre sur un portrait de la famille, écrit en 1981 par François Heugel, l'arrière petit-fils du fondateur Jacques-Léopold. Il comprend un arbre généalogique (p. 9) qui nous conduit de Christian (1764-1811) jusqu'aux premières années du XXe siècle. Cette introduction parle des activités quotidiennes de Jacques-Léopold et sert aussi à présenter quelques-unes de ses connaissances à la fois professionnelles et personnelles. Elle décrit aussi la transmission du commerce à Henri, fils de Jacques-Léopold en 1883, et de leur fonds d'acquisitions, ce qui a contribué à l'agrandissement de la maison.

À partir de débuts modestes - la publication du journal hebdomadaire Le Ménestrel en 1839 -, la maison est encore active aujourd'hui et publie présentement les oeuvres de compositeurs comme Amy, Boulez et Jolas, aussi bien que des publications musicologiques comme Le pupitre. ${ }^{1}$

Le volume est organisé de manière adéquate. Les lettres sont classées en trois grandes sections ; 1 . Le milieu éditorial, 2. Autour du journal « Le Ménestrel ", et 3 . A propos de quelques grands maîtres. Chacune de ces sections sont, à leur tour, subdivisées ( "Offres diverses 》, "Remerciements ", classement par auteur). La plupart des lettres incluent l'adresse du destinataire et la date.

L'index comprend aussi deux autres listes qui facilitent la recherche des références. L'une donne tous les correspondants de la famille Heugel avec les dates et les professions; l'autre inventorie tous les noms cités.

Parmi les lettres particulièrement intéressantes, citons celle de Vincent d'Indy (No 60, p. 91) où il parle d'un portrait de César Franck, et une autre (No 54, p. 86) écrite par Ernest Guiraud, au sujet d'un projet de monument funéraire pour Bizet avec lequel il entretenait des liens d'amitié. Le livre contient aussi des notes copieuses après chaque lettre. Elles intéresseront le spécialiste, comme cette information concernant $M$. Bessel, un éditeur russe, qui a écrit dans la revue Nouveau Temps, et qui a été accusé par César Cui d'avoir confisqué ses droits d'auteur français (Lettre du 12 janvier 1891, pp. 73-4). Parmi les autres compositeurs dont les lettres sont publiées, citons Jules Massenet, Ambroise Thomas et Camille Saint-Saens.

Des lettres pittoresques et plaisantes, nous retiendrons celle-ci, écrite par le compositeur du Barbier de Séville : « Rossini prie son ami Heugel de faire acte de dévouement en dînant chez lui demain samedi 27 septembre. 
On ne recevra pour excuse qu'une réponse favorable. Nous signons Heugel ou la mort. " (Lettre No 37, p. 64).

Susan Spier

\section{NOTE}

1. Cf. l'article du New Grove Dictionary of Music and Musicians consacré à la maison Heugel (vol. VIII, p. 359).

Nikolaus Harnoncourt. Le discours musical. Pour une nouvelle conception de la musique. Traduit de l'allemand par Dennis Collins. Paris : Gallimard, 1984. (Musik als Klangrede. Wege zu einem neuen Musikverständnis, Residenz Verlag, Salzburg und Wien, 1982) 298 pp., ex. musicaux.

Voilà un livre qui devrait, si ce n'est déjà fait, produire quelque sensation parmi le grand public et les musiciens, du moins chez ceux qui auraient envie de reconsidérer leurs vues sur la musique dite " ancienne".

Car il s'agit bien d'un livre provocateur et d'intérêt général. Sa présentation reflète cette intention. Il s'agit en effet d'une série d'articles, de conférences et de cours assemblés en une suite de chapitres brefs, dont le ton relève par conséquent du langage parlé plus que du discours musicologique. La lecture du Discours musical est donc facile, rapide, journalistique : on vise le grand public. Le défaut de ce recueil est son côté répétitif qui, s'il peut avoir des vertus pédagogiques, peut finir par lasser le lecteur, déjà effrayé par le prix de l'ouvrage, et dès lors inquiet de retrouver les mêmes idées d'un chapitre à l'autre.

Mais il ne s'agit pas de faire thèse : pamphlet plutôt. L'ouvrage devient alors difficile à résumer. Par chance, l'auteur y fait preuve d'une constance inébranlable. Le premier article, "La musique dans notre vie " , est un discours prononcé en 1980, alors que le suivant, "L'interprétation de la musique historique ", date de 1954. Ce dernier forme le credo du Concentus Musicus de Vienne fondé par Harnoncourt. Et ce credo, depuis trente ans, est resté le même : credo ? Manifeste mêlé de polémique qui provoque notre paresse, comme l'incuriosité souvent agressive de certains musiciens dits " classiques ».

La thèse est claire et énergique. "La musique est devenue un simple ornement ", déclare l'auteur. "Elle ne doit en aucun cas déranger, nous effrayer (pp. 9 et 10). Domestiquée, destinée au plus grand nombre, privée de son sens premier, de sa provocation première, elle se verra réduite à sa seule beauté. La musique actuelle dérange : on se tournera vers la musique " historique » qui fournit la quasi-totalité du répertoire des concerts et des maisons d'enseignement. Ramenées sous l'égide d'une ronronnante et confortable beauté, les singularités des styles, des époques et des pays 